\title{
POPULAR POR SUBTRAÇÃO \\ NOTAS PARA UMA RELEITURA DE CÂMARA CASCUDO
}

\section{Andrea Ciacchi (UFPB)}

Um texto clássico e nunca suficientemente conhecido, como Literatura oral no Brasil, de Luís da Câmara Cascudo, talvez o mais metodologicamente rigoroso na obra do erudito potiguar, está sempre despertando novas leituras, solicitando renovadas abordagens críticas entre os pesquisadores que se dedicam ao horizonte delicado da cultura popular brasileira. Aqui, muito sucintamente, e sem nenhuma pretensão de alcançar rigor analítico ou de esgotar o conjunto das questões levantadas pelo texto, desejo apenas resenhar alguns marcos que definem opções e visões do autor, extraindo-os das páginas que constituem o primeiro capítulo do livro.

$\dot{E}$ evidente que as idéias centrais desenvolvidas no primeiro capitulo de Literatura oral no Brasil' se aglutinam em volta das suas perspectivas teóricas e metodológicas, todas elas inspiradas pelas noções de "sobrevivência", "anonimato", tradição "estagnada", comparativismo. Nas páginas que pretendo discutir, adquirem ênfase expressões como "temas remotos" (p. 22, $5^{\circ}$ parágrafo), "antiguidade", "persistência" e "anonimato" (p. 23, $2^{\circ}$ par.), "indecisão cronológica" (p. 23, 3 par.), "memória coletiva, indistinta" e "sobrevivência" (p. 23, 40 par.), "cultura que [...] bebeu no leite da antiguidade" (p. 25, 40 par.), "menestréis da idade média" e "conservação ciumenta" (p. 26, 50 par.) etc. Resumindo como resumiram Marcos Ayala e Maria Ignez N. Ayala², "em outros termos, um conjunto de resíduos, de fragmentos de costumes e práticas culturais desaparecidas. Assim, torna-se dificil estabelecer os vínculos entre as manifestações populares e os contextos em que surgiram".

Ora, em 1952, quando Literatura Oral foi publicado pela primeira vez, a penetração da dialética nos estudos sociais, por um lado, e o interesse da sociologia em explorar as manifestações da

Utilizo a 2. ed. Rio de Janeiro: José Olympio, 1978.

Cultura popular no Brasil. Sào Paulo: Ática, 1986, p. 15. 
cultura popular eram fatos ainda raros no Brasil. Assim, não se trataria aqui de "cobrar" de Câmara Cascudo um posicionamento mais "problematizador", mais alinhado com o que hoje consideramos a justa contextualização dos fatos folclóricos. Antes, parece mais útil esboçar algumas reflexões que poderiam ter alguma utilidade para futuras discussões.

Em primeiro lugar, como é óbvio, o que está ausente desse capítulo, desse livro, de boa parte da obra de Câmara Cascudo e, enfim, ausente de toda essa orientação teórico-metodológica que, no Brasil, nos acostumamos a chamar de "folclorismo", o que está ausente é exatamente o Brasil das relações de trabalho, ou seja o Brasil das classes sociais. Em nenhum trecho desse texto, parece-me, atenta-se para a correspondência (a "solidariedade sócio-cultural", diria Cirese $^{3}$ ) entre diferentes manifestações culturais e diferentes estratos sociais. Tão-somente quando frisa a "diferença", o autor encaminha a discussão para uma oposição "virtual" (pois não explicitada) entre "antigo" e "moderno", entre "ágrafo" e "erudito", entre algo que não consegue definir e a cultura "oficial". Veja, a esse respeito, sobretudo, o final da pág. 25. Por trás de cada manifestação mencionada por Câmara Cascudo, não se enxerga ninguém: nem mulheres nem homens reais. Ao contrário, quando o autor empenha-se em descrever as várias disciplinas da cultura não-popular (como faz no primeiro parágrafo da mesma página 25), estamos diante de uma galeria de "arqueólogos", "sociólogos", "antropólogos", "eruditos da novelística", "músicos", "médicos" etc. Em outras palavras, a literatura oral parece "fazer-se por si mesma", emergindo dessa zona indistinta e dotada de vitalidade própria que é o passado. Já a cultura "oficial" essa, é feita por homens vivos, atuantes, protagonistas da sociedade "real" e "moderna". Num parágrafo revelador das dificuldades acarretadas por essa orientação, Câmara Cascudo deixa entrever a distância que corre entre esferas culturais que, na realidade, estão distantes, antes, no plano histórico-social: "Ninguém deduzirá como o povo conhece a sua literatura e defende as características imutáveis dos seus gêneros. É como um estranho e misterioso cânon para cujo conhecimento não fomos iniciados" (p. 26, 4\% par. - grifos meus). Essa iniciação será porventura ligada ao conhecimento dos processos "específicos de criação" de que, alguns anos antes, já havia falado Amadeu Amaral (em Tradiçòes populares)? Em caso

Cultura egemonica e culture subalterne. Palermo: Palumbo, 1979. 
afirmativo, teríamos, à revelia do próprio autor, a revelação de uma "incomunicabilidade" cultural derivada, antes, de uma distância social e econômica. Mas não se poderia esperar de Câmara Cascudo (e de poucos, aliás, no Brasil provinciano daqueles anos 50) que se atentasse para as relações imediatas e necessárias entre "produção e reprodução da vida material" e a "vida espiritual", para usarmos o dicionário dos dialéticos.

Paradoxalmente, porém, o texto de Câmara Cascudo contém, também meio à revelia, uma trilha áspera que poderia levar o autor para fora do terreno movediço em que se meteu. Ao citar com ênfase o folclorista e antropólogo francês Pierre Santyves, acaba, num primeiro momento (p. 24), aceitando uma espécie de declaração de cidadania para a consideração das "condições materiais" no estudo da cultura popular. Cito, traduzindo-o, um trecho do Manuel de Folklore (1933) de Santyves transcrito pelo próprio Câmara Cascudo: "Querer reservar o nome de folclore para cultura espiritual e opô-la à etnografia tomada no seu sentido de cultura material equivale a querer romper uma unidade realmente orgânica". As manifestações da literatura oral, parece dizer-nos Santyves (mas não a Câmara Cascudo), não são separadas da vida material de quem as pratica. Mais contundente parece-me o trecho do Manuel citado à pág. 30. Diz o Santyves: "O folclore estuda a vida popular, mas no interior da vida civilizada. Não há matéria folclórica junto às populações nas quais não se pode distinguir entre duas culturas, a da classe instruída e a da classe popular" (grifo meu). O contexto de Santyves ainda está ligado a uma idéia de popular como antigo, atrasado, "não-civilizado", porém a vinculação da existência da cultura popular à existência de uma estratificação social é clara, e provavelmente incompreendida e incompreensivel para Câmara Cascudo. Valeria lembrar, nessa perspectiva, que o próprio Manual de folclore de Santyves (aqui citado e traduzido por Giuseppe Cocchiara em sua Storia del Folklore in Europa ${ }^{4}$ ) afirma em outro lugar: "A tradição popular não se pode comparar a um tesouro enterrado: é um fluxo de riquezas de toda ordem, uma transmissão sem fim de milhares e milhares de invenções humanas de que o povo se beneficia nas nações civilizadas. A corrente de ouro da tradição não repousa imóvel num escrínio lacrado, mas realiza, assim como os astros, o milagre do movimento perpétuo". De forma algo astronômica..., o autor parece aqui reconhecer a cultura

4. ed. Torino: Boringhieri, 1972, p. 532. 
popular como fruto de um processo "real" de mudanças, transformações, não apenas uma "sobrevivência" do passado. Não se trata, evidentemente, de transformar Santyves num "campeão" da demologia moderna, mas acho interessante mostrar que haveria algo de mais desenvolvido na visão desse que foi uma das fontes de inspiração para a perspectiva teórico-metodológica de Câmara Cascudo.

A segunda observação que me parece cabível também aponta para um aparente paradoxo. Nisso também Câmara Cascudo é "companheiro de viagem" de outros folcloristas brasileiros, tanto os que o influenciaram como os que ele próprio influenciará - mas também de estudiosos europeus da segunda metade do século XIX. No afã de demonstrar o caráter de sobrevivência da cultura popular, produzida, como ela seria, por sobras de fatos culturais do passado erudito (e que o pesquisador contemporâneo tem como tarefa reconstruir, nas suas etapas, através, quiçá, daquela famosa "imaginação adivinhadora"), acaba-se (sem querer, talvez, em muitos casos) por negar capacidade criadora e autonomia estética (se não, mais amplamente, cultural) às classes populares. Tenho insistido muito no desmascaramento desse paradoxo (na realidade um traço ideológico claríssimo) nas minhas atividades acadêmicas, justamente porque o raciocínio (como qualquer construção ideológica - uma ilusão bem fundada nas aparências) é muito perigoso. Quando aparentemente enaltece ("olha como é 'nobre' a 'origem' do folclore brasileiro...!"), na realidade avilta ("o povo não sabe criar, quando muito re-cria"...). Encontro uma definição arguta desse impasse numa página de Cireses:

A esse trabalho de investigação histórica, sem dúvida proficuo [refere-se às pesquisas italianas sobre a "poesia popular antiga" empreendidas por volta de 1870], acompanha-se entretanto uma postura ideológica muito evidente: exalta-se a "beleza" da poesia popular "antiga", e recusa-se, por outro lado, a tradição oral contemporânea, apreciada somente se corresponde aos modelos antigos. e Silvio Romero]. Chega-se sobretudo, Celso de Magalhães o fez [o poeta italianoga-se a declarar explicitamente (como moderno" não canta, pos-romântico] Carducci) que o "povo O mito romântico do "povo criador" Op. cit. p. 160-161. 
contradição consigo mesmo: como é possivel que esse idolatrado "povo" foi criador no passado e deixou de sê-lo no presente? À origem dessa postura está sem dúvida a crise social que se anunciava na Itália de então [ $e$ que, assumimos, não era tão diferente do Brasil dessa mesma época e das décadas sucessivas]. O "povo" contemporâneo começa a amedrontar, e por isso parece bom intentar essa fuga para o passado: identifica-se o "povo" do passado com a burguesia nascente, recusando a possibilidade de reconhecê-lo nas classes agrárias modernas.

Assim, povo bonito é povo do passado, possivelmente morto e enterrado. Povo bom é esse que só faz repetir o passado, o bom e velho passado em que a ordem social não esteve em discussão. À raiz desse equívoco, parece-me, está também a dificuldade (que se mantém nos nossos dias), demonstrada por muitos folcloristas, de "ver" a cultura popular nas cidades, nas áreas urbanas, nas fábricas etc. ${ }^{6}$

Não deve ter sido esse, provavelmente, o intuito consciente de Câmara Cascudo, embora não seja difícil relacionar esse perigo ideológico com a situação de proximidade da sua figura com o conjunto (ideológico, cultural, político) paternalista e conservador da elite nordestina em tempos de crise da economia açucareira. Vale, porém, ressaltar de novo que o impasse é particularmente ardiloso. pois numa visão oriunda de uma espécie de ancien régime colonial, antigüidade é sintoma de nobreza, sinal de reconhecimento, patente de bons antecedentes culturais. O repentista é "herdeiro" de não sei que poeta grego ou menestrel medieval... A Grécia clássica e a Idade Média cristã, duas lacunas lamentáveis no passado de um país que, se olha para trás, só vê indio! Deve ter sido bom "resgatar" esses momentos altos da história ocidental, nem que fosse através de gente "rude", "simples", milagrosamente imbuída do espírito dos grandes artistas do passado europeu. A literatura oral brasileira, assim, parece meio "psico-grafada", ou melhor, "sócio-grafada", vinda diretamente do passado, pulando as etapas da contextualização histórica e sociológica. Mais uma vez, ao que me parece, idéias (literalmente) fora do lugar.

6 Veja a esse propósito: AYALA, Maria Ignez Novais. Por uma abordagem critica do popular. Graphos; Revista da Pós-Graduação em Letras da UFPB. João Pessoa, vol. II, n. 4, p. 36-45, jun. 1997. 
Acresce-se, assim, um outro impasse. Além da contradição do mito romântico do povo criador e poeta, anuncia-se outra: a contradição dos vínculos entre folclore e identidade nacional. Como é possível que a cultura popular (brasileira) seja erguida, simultaneamente, a resumo, síntese, símbolo e summa da verdadeira cultura nacional, "marco identitário" de um país que se compraz em não enxergar os seus conflitos, se ela é feita de matéria histórica e geograficamente alheia? O brasileiro "se pertence" ou é de outrem? A contradição (que mereceria, evidentemente, uma formulação mais clara e ampla) atinge sobretudo esse "nacionalismo ibérico-popularesco" de um Ariano Suassuna, mas é fruto também de uma longa tradição de posicionamentos teóricos e metodológicos que não puderam (em alguns casos, não quiseram) dar conta da complexidade real, essa que só se destrinça recorrendo à dialética. Afinal, o folclore brasileiro é (para parafrasear Euclides da Cunha) um "epítome vivo" do país, ou, antes, mera cópia de modelos ao mesmo tempo antigos e estrangeiros? Ainda com o empréstimo de uma reflexão de Roberto Schwarz ("Nacional por subtração" - texto famoso? em que essas questões são bem mais profundamente expostas e discutidas), esse folclore é "postiço, inautêntico [e] imitado", ou orgulho nacional de um país sem classes, sem história e sem contextos?

Finalmente, parece lícito concluir que a releitura desse texto de Câmara Cascudo, ao mesmo tempo que lhe desnuda impasses, equívocos e problemas, permite estabelecer uma pauta aceitável de discussão, apontando para temas e orientações teóricas e metodológicas que se situam numa convergência ideal de estudos estéticos, literários e filológicos (talvez o terreno preferido pelo próprio autor de Literatura Oral no Brasil) e implicações sociológicas, antropológicas e historiográficas, desde que (ao menos na minha irrenunciável perspectiva de estudo) unificadas pelo recurso ao único instrumento capaz de desmascarar, contornar e eliminar os riscos ideológicos: a dialética sempre atualizada que busca reconhecer o movimento incessante das relações econômicas da sociedade no reflexo das atividades culturais.

Cf. Que horas são? Ensaios. São Paulo: Companhia das Letras, 1987. 